\title{
Structural, microstructural and thermal properties of lead-free bismuth-sodium- barium-titanate piezoceramics synthesized by mechanical alloying
}

\author{
Rasool Amini a,*, Mohammad Reza Ghazanfari ${ }^{a}$, Morteza Alizadeha ${ }^{a}$, Hamed Ahmadi Ardakani ${ }^{a}$, \\ Mohammad Ghaffari ${ }^{\mathrm{b}}$ \\ ${ }^{a}$ Department of Materials Science and Engineering, Shiraz University of Technology, 71557-13876 Shiraz, Iran \\ ${ }^{\mathrm{b}}$ Department of Electrical and Electronics Engineering, UNAM-National Institute of Materials Science and Nanotechnology, Bilkent University, Ankara 06800, Turkey
}

\section{A R T I C L E I N F O}

Article history:

Received 31 May 2012

Received in revised form 4 November 2012

Accepted 5 November 2012

Available online 14 November 2012

\section{Keywords:}

A. Ceramics

A. Nanostructures

A. Electronic materials

D. Phase equilibria

D. Microstructure

\begin{abstract}
A B S T R A C T
Bismuth-sodium-barium-titanate piezoceramics with a composition of $\left(\mathrm{Bi}_{0.5} \mathrm{Na}_{0.5}\right)_{0.94} \mathrm{Ba}_{0.06} \mathrm{TiO}_{3}$ (BNBT) were prepared by mechanical alloying (MA). Structural analysis and phase identification were performed by X-ray diffraction (XRD). Microstructural studies and chemical composition homogeneity were performed by scanning electron microscope (SEM) coupled with energy dispersive X-ray analysis (EDX). Furthermore, thermal properties of the as-milled powders were evaluated by thermogravimetry/ differential thermal analysis (TG/DTA). During the initial milling, the constituents were transformed to the perovskite, pyrochlore, and BNT phases; in addition, partial amorphization of the structure appeared during the milling cycle. As MA progressed, transformation of pyrochlore-to-perovskite and crystallization of the amorphous phase occurred and also, the BNBT phase was significantly developed. It was found that the MA process has the ability to synthesize the BNBT powders with a submicron particle size, regular morphology, and uniform elemental distribution.
\end{abstract}

(c) 2012 Elsevier Ltd. All rights reserved.

\section{Introduction}

Lead-based piezoceramics such as lead titanate (PT) and lead zirconate titanate (PZT) are widely used in commercial applications due to their significantly high piezoelectric properties [1-3]. Considering the toxicity of lead-based ceramics, negative human health impacts and possibility for environmental pollutants that can be caused over their lifecycle, it is clear a substitute is needed [4,5]. $\mathrm{Bi}_{0.5} \mathrm{Na}_{0.5} \mathrm{TiO}_{3}$ ceramics (BNT) with an $\mathrm{ABO}_{3}$ perovskite structure are known as appropriate substitute to the lead-based piezoelectric materials [6]. Although the BNT compound exhibits high Curie temperature and considerable ferroelectric properties, it has very low polarizability and piezoelectric properties which result in its relatively high coercive field [7]. It is well known that the piezoelectric properties of BNT ceramics can be significantly improved by an addition of barium ( $\mathrm{Ba}$ ) provided that the composition is located at the Morphotropic Phase Boundary (MPB) region $[8,9]$. In the $\left(\mathrm{Bi}_{0.5} \mathrm{Na}_{0.5}\right)_{1-x} \mathrm{Ba}_{x} \mathrm{TiO}_{3}$ compound (BNBT), the composition will be located at the tetragonal boundary of MPB where the quantity of $x$ is close to $6[10,11]$.

Although BNBT ceramics are commonly synthesized by the convectional mixed oxides routes [12-14], the difficulty to achieve

\footnotetext{
* Corresponding author. Tel.: +98 917811 1858; fax: +98 7117354520 .

E-mail addresses: amini@sutech.ac.ir, ramini2002@gmail.com (R. Amini).
}

the proper compositional homogeneity is the main limitation of these methods $[14,15]$. BNBT can be produced by various chemical methods [16-18] which have disadvantage like expensive precursors and complexity of processing parameters $[19,20]$. Mechanical alloying (MA) is one of the solid state routes employed extensively to produce structures far from their equilibrium states such as supersaturated solid state solutions, amorphous phases, and nanocrystalline materials [21-23].

During MA, powder particles are subjected to severe plastic deformation and repeated cold welding and fractures which promote atomic scale alloying [22,23].

In the case of ceramics processing, MA was successfully utilized to produce the materials in powder form with a nanocrystalline structure and high compositional homogeneity [24-30]. By employing this method, not only the desired structure can be directly formed without any further processing, but also the calcination process which is typically required in the solid state routes can be reduced [31]. In the case of BNBT, scientific efforts have rarely been conducted on its processing by mechanical routes and, to the best of our knowledge, no systematic work has been performed on the characterization of these advanced materials synthesized by MA. This study is able to demonstrate for the first time the possibility to synthesize the BNBT ceramics with the desired structure by utilizing MA. To achieve this, the structural, microstructural, and thermal properties of the alloyed powders were evaluated. 


\section{Experimental procedure}

In order to synthesize the BNBT compound, high purity (>99.5\%) materials consisting of $\mathrm{TiO}_{2}, \mathrm{Bi}_{2} \mathrm{O}_{3}, \mathrm{BaO}$, and $\mathrm{Na}_{2} \mathrm{CO}_{3}$ were mixed according the BNBT stoichiometric ratio of 35.88:48.98:4.11:11.06 and then milled in dry conditions under air atmosphere. For a better explanation of the synthesis steps, a relatively low-energy ball mill was employed to perform the MA process. The milling process was performed in a planetary ball mill (Sepahan $84 \mathrm{D}$ ) with a tempered steel bowl (capacity $=90 \mathrm{ml}$ ) at a rotation speed of $180 \mathrm{rpm}$ using four tempered steel balls with diameter of $20 \mathrm{~mm}$ and seven tempered steel balls with diameter of $8 \mathrm{~mm}$ giving a ball to powder mass ratio of 20:1. Samples were obtained at different milling times, the longest being $360 \mathrm{~h}$.

The structural phase analysis was carried out using an X-ray diffractometer (XRD, Bruker Advance 2) using a $\mathrm{Cu} \mathrm{K} \alpha_{1,2}$ radiation set at $40 \mathrm{kV}$ and $40 \mathrm{~mA}$ at room temperature with a $2 \theta$ range of 20 $70^{\circ}$ with step size and rate of $0.03^{\circ}$ and $6 \mathrm{~s}$ respectively. The microstructural features, morphology, particle size, and homogeneity in the elemental distribution during MA were investigated by a scanning electron microscope (SEM, JEOL-JSM 6349F) coupled with an energy dispersive X-ray spectrometer (EDX) under $10 \mathrm{kV}$ accelerating voltage, $10 \mathrm{pA}$ probe current, $10 \mathrm{~mm}$ working distance, and zero degree tilting angle. Finally, thermogravimetry (TG) and differential thermal analysis (DTA) were done at temperature ranges between $300{ }^{\circ} \mathrm{C}$ and $900{ }^{\circ} \mathrm{C}$ with a heating rate of $20^{\circ} \mathrm{C} / \mathrm{min}$, in an air atmosphere using a simultaneous thermal analyzer (Shimadzu, DTG-60H).

\section{Results and discussion}

Fig. 1 illustrates the XRD results of the alloyed powders as a function of milling time. According to the XRD profile of the mixed primary materials, sharp peaks of anatase $\left(a-\mathrm{TiO}_{2}\right)$, rutile $\left(\mathrm{r}-\mathrm{TiO}_{2}\right)$, $\mathrm{Bi}_{2} \mathrm{O}_{3}, \mathrm{Na}_{2} \mathrm{CO}_{3}$, and $\mathrm{BaO}$ are detectable. By starting the milling process, the peak broadening of the initial materials enhances at different rates where that of the $\mathrm{Na}_{2} \mathrm{CO}_{3}$ and $\mathrm{Bi}_{2} \mathrm{O}_{3}$ phases is more significant. It can be attributed to the combination of several reasons such as (a) a decrease in the crystallite size of initial materials [22], (b) an increase in the lattice strain of these

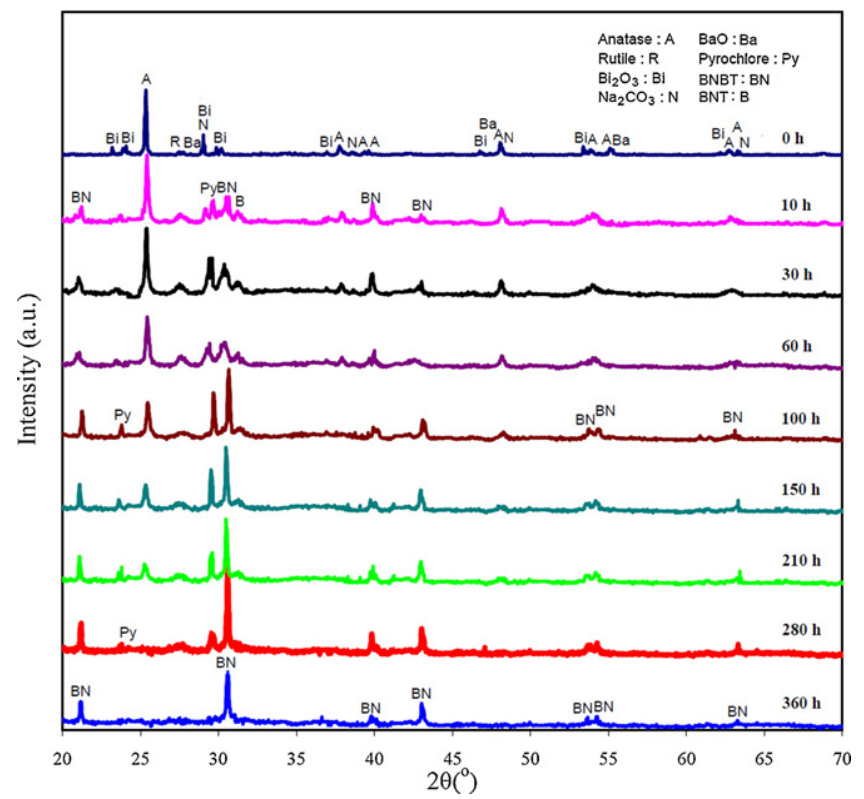

Fig. 1. X-ray diffraction patterns of the initial and as-milled powders at different times. materials, and (c) an amorphous phase formation during milling [23]. Further examination of the XRD pattern of the $10 \mathrm{~h}$ milled powders indicates that despite the utilization of a relatively low energy milling, several peaks of perovskite BNBT (around $2 \theta=22^{\circ}$ and $2 \theta=31^{\circ}$ ), pyrochlore (around $2 \theta=29^{\circ}$ and $2 \theta=29.5^{\circ}$ ), and perovskite BNT (around $2 \theta=31.5^{\circ}$ ) with low intensity and sharpness are detectable. Accordingly, it can be inferred that at this time interval, the main phenomenon is the direct transformation of the primary materials to the above mentioned phases. Since the perovskite lattice is expanded by Ba doping, the BNBT peaks are located at lower degrees $(2 \theta)$ toward the BNT peaks. That is, the BNBT peaks can be discriminated from BNT ones, although it seems that distinguishing between the XRD peaks of the BNBT and BNT phases is quite difficult. Increasing milling time to $30 \mathrm{~h}$, the peak broadening of the final phases as well as initial materials increases; moreover, due to an increase in the atomic plan spacing $(d)$ caused by strain [23,32], the peak locations shift to slightly lower $2 \theta$ angles. At the moment, it can be seen that the peaks of pyrochlore broaden (at range of $2 \theta=29-30^{\circ}$ ) noticeably in comparison to the other present phases. The non-stoichiometric nature of pyrochlore allows the possibility of pyrochlore formation with a different composition in which their peaks can overlap with each other and consequently, these multiple peaks appear as a single broad peak [33].

Looking at the XRD pattern of the $30 \mathrm{~h}$ milled sample, the existence of a broad peak around $2 \theta=32^{\circ}$, probably related to the (1 111 ) reflection of metastable $\mathrm{s}-\mathrm{TiO}_{2}$ (srilankite) phase produced from polymorphic transformation of the anatase phase during MA is evident. Since the srilankite diffraction peaks are usually broadened due to nanometric crystallites containing a large amount of lattice strain and since the amount of the phase is considerably low, other reflections of the phase are not detectable in the XRD pattern $[34,35]$.

Examining the $60 \mathrm{~h}$ pattern, while the increase in peak broadening continues, it can be observed that due to the presence of a high amount of amorphous phase in the structure, the high angle peaks $\left(2 \theta>50^{\circ}\right)$ disappear [22]. At $100 \mathrm{~h}$ of milling, the peak sharpness of the initial phases diminishes, while the sharpness of pyrochlore and especially of the BNBT peaks increases considerably, and due to the crystallization of amorphous phase, the high angle peaks become visible. Comparing the XRD patterns of the $100 \mathrm{~h}, 150 \mathrm{~h}, 210 \mathrm{~h}$, and $280 \mathrm{~h}$ milled samples reveals that by increasing milling time, possibly because of the pyrochlore-toperovskite phase transformation, the peak intensity of BNBT increases and the peak for pyrochlore reduces. In addition, it can be seen that due to the dissolution and/or transformation of initial phases, the srilankite, $\mathrm{BaO}, \mathrm{Na}_{2} \mathrm{CO}_{3}, \mathrm{Bi}_{2} \mathrm{O}_{3}$, and $\mathrm{BNT}$ peaks disappear completely after $210 \mathrm{~h}$ of milling and also, the anatase peaks entirely disappear after $280 \mathrm{~h}$ of milling. Finally, the alloying process is completed after $360 \mathrm{~h}$ milling where the residual peaks of the rutile and pyrochlore phases diminish.

Based on the aforementioned results, it is evident that considerable energy of the milling process is consumed by polymorphic transformations of $\mathrm{TiO}_{2}$, and consequently it can be concluded that these transformations act as a main impediment of the alloying process during milling which can be easily resolved by utilization of $\mathrm{r}-\mathrm{TiO}_{2}$ (rutile) instead of a- $\mathrm{TiO}_{2}$ (anatase) in the initial powder mixture.

Fig. 2 shows the SEM micrographs of the milled powders at different milling times. The images reveal that as milling time increases, the powders' morphology becomes equiaxed and their particle size is continuously decreased. After $360 \mathrm{~h}$ of milling, the alloyed powders have an average particle size of $380 \mathrm{~nm}$, ranging from $250 \mathrm{~nm}$ to $1100 \mathrm{~nm}$.

The EDX elemental distribution maps and spectrums of $30 \mathrm{~h}$ and $280 \mathrm{~h}$ milled powders are shown in Fig. 3(a) and (b), respectively. Concerning the results, it can be seen that in the 

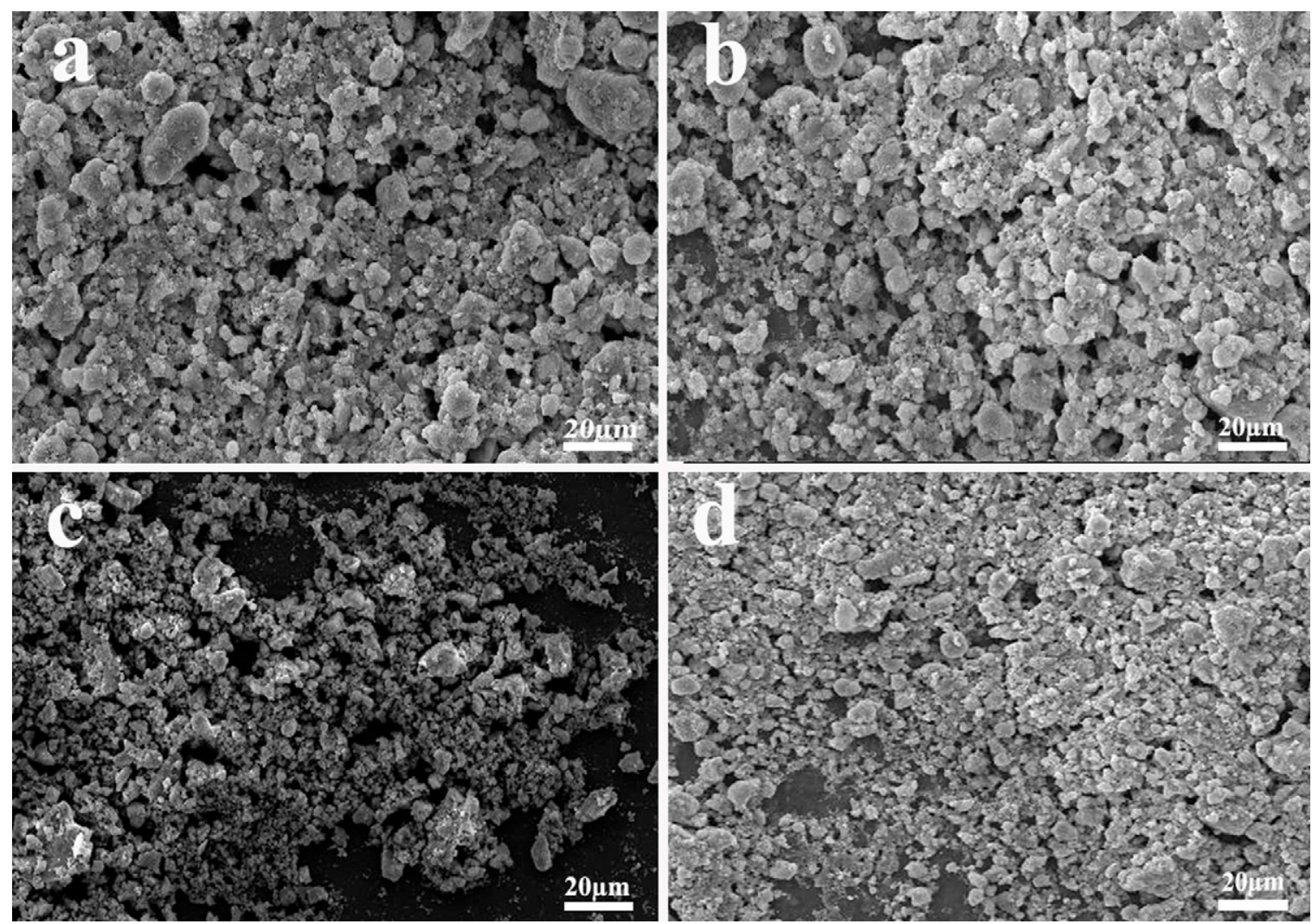

Fig. 2. SEM micrographs of BNBT powder after (a) $1 \mathrm{~h}$, (b) $60 \mathrm{~h}$, (c) $210 \mathrm{~h}$ and (d) $360 \mathrm{~h}$ of milling.

$280 \mathrm{~h}$ milled powder, the constituent elements are homogeneously distributed in the powders; on the contrary, in the $30 \mathrm{~h}$ milled powders, the distribution of the elements is not sufficiently homogeneous. By focusing on the EDX spectrum, it can be clearly
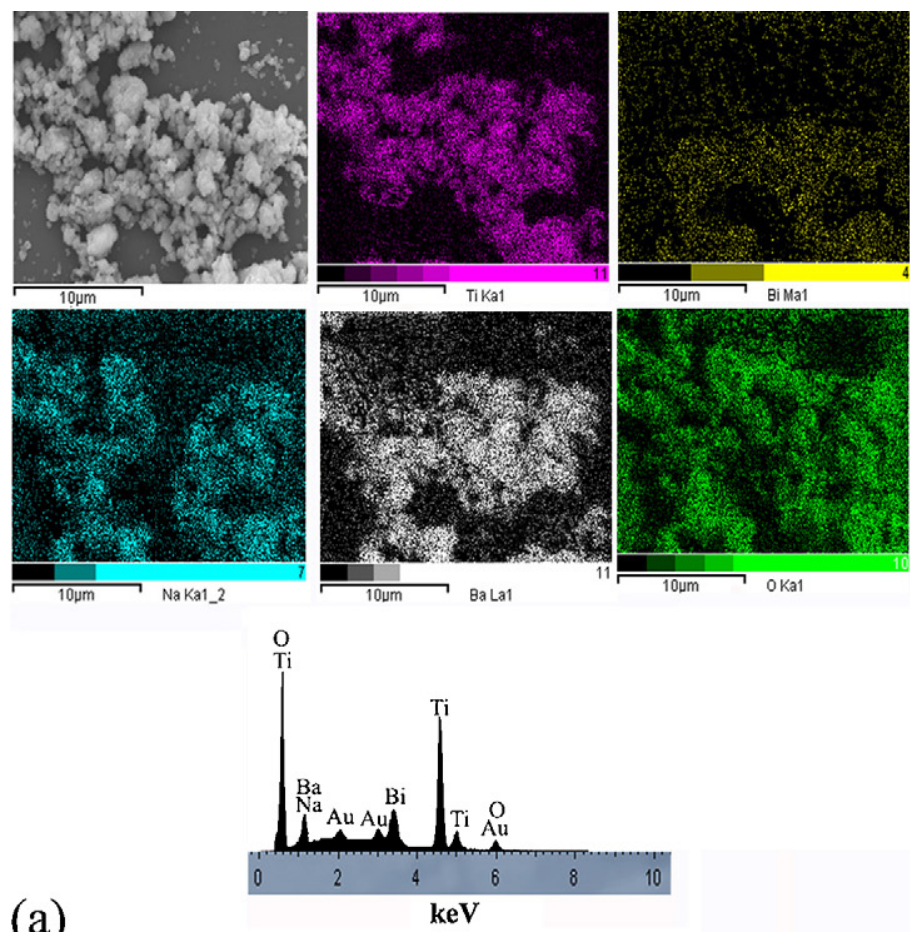

(b)
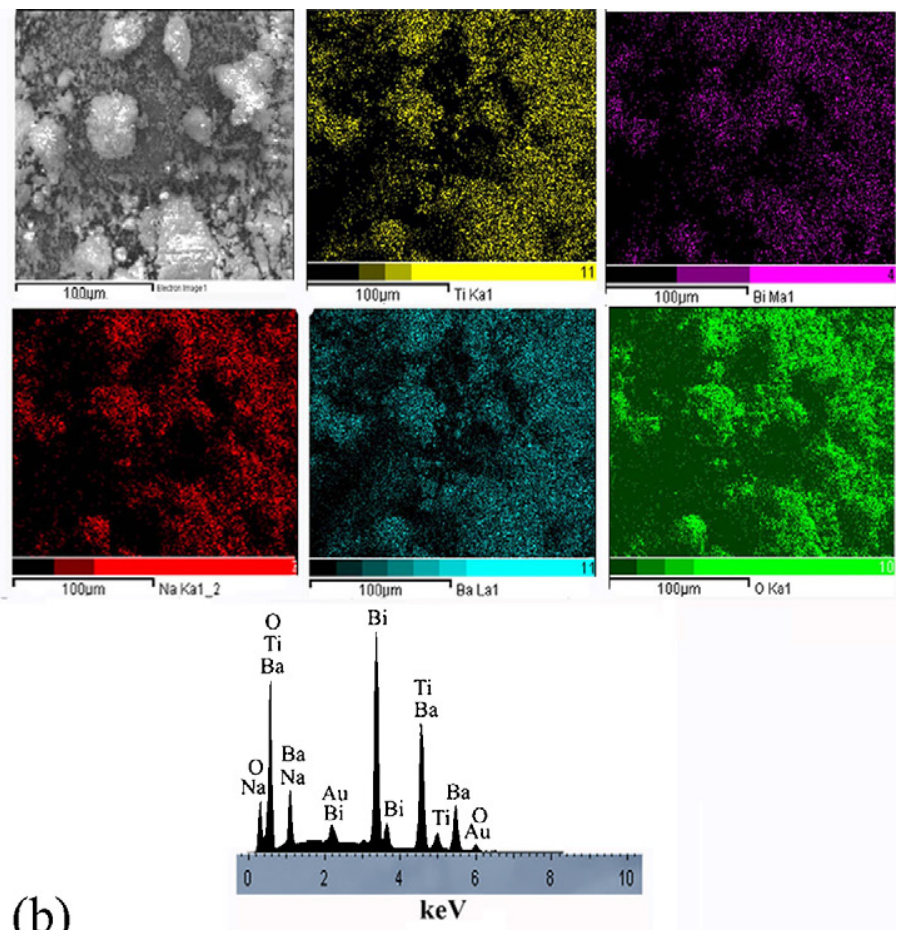

(a)

Fig. 3. EDX elemental map and spectrum of (a) $30 \mathrm{~h}$ and (b) $280 \mathrm{~h}$ milled powders 


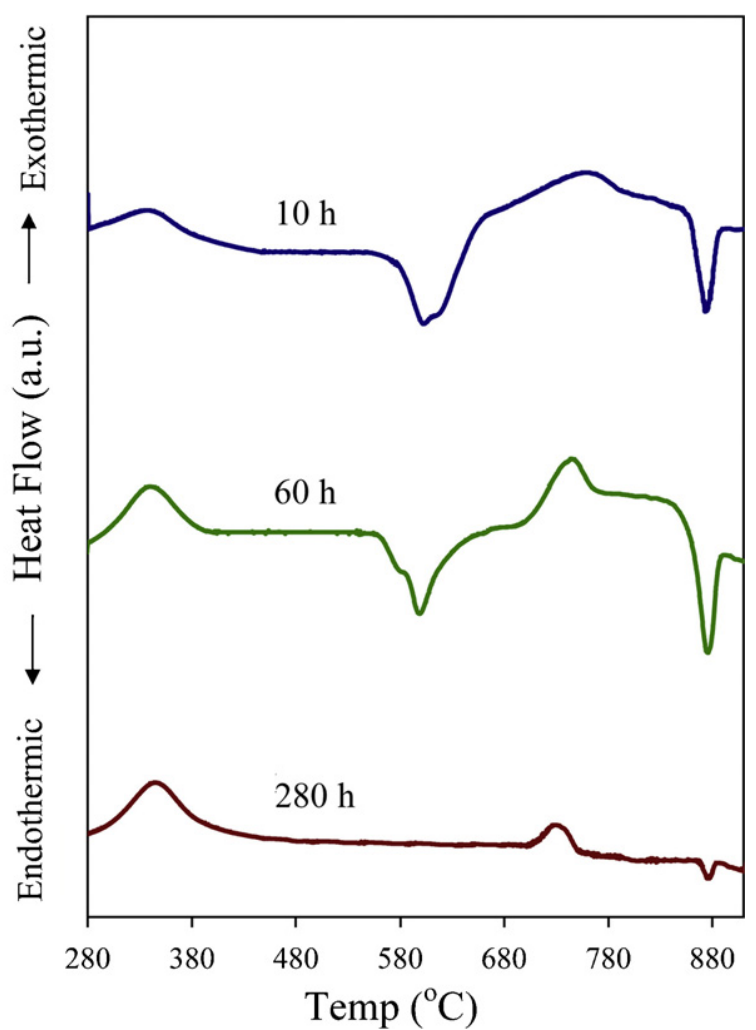

Fig. 4. DTA results of the powders at different milling times.

at relatively short milling times, however, as milling lengthens, composition uniformity improves.

In order to evaluate the thermal behavior of the as-milled powders, the DTA/TG test used a constant heating rate of $20^{\circ} \mathrm{C} /$ min. All the samples were heated up to $910^{\circ} \mathrm{C}$ (on the first run) and then cooled down to $100{ }^{\circ} \mathrm{C}$. Afterwards, the second heating run was conducted to establish the base line measurement. Fig. 4 illustrates the DTA results of the samples milled for $10 \mathrm{~h}, 60 \mathrm{~h}$, and $280 \mathrm{~h}$ at a temperature range of $300-910^{\circ} \mathrm{C}$. It is clear, the sample milled for $10 \mathrm{~h}$ displays two exothermic peaks (around $350{ }^{\circ} \mathrm{C}$ and $750{ }^{\circ} \mathrm{C}$ ) as well as four endothermic peaks (around $540{ }^{\circ} \mathrm{C}, 608^{\circ} \mathrm{C}$, $622^{\circ} \mathrm{C}$, and $875^{\circ} \mathrm{C}$ ) in the DTA profile. As milling progresses, the

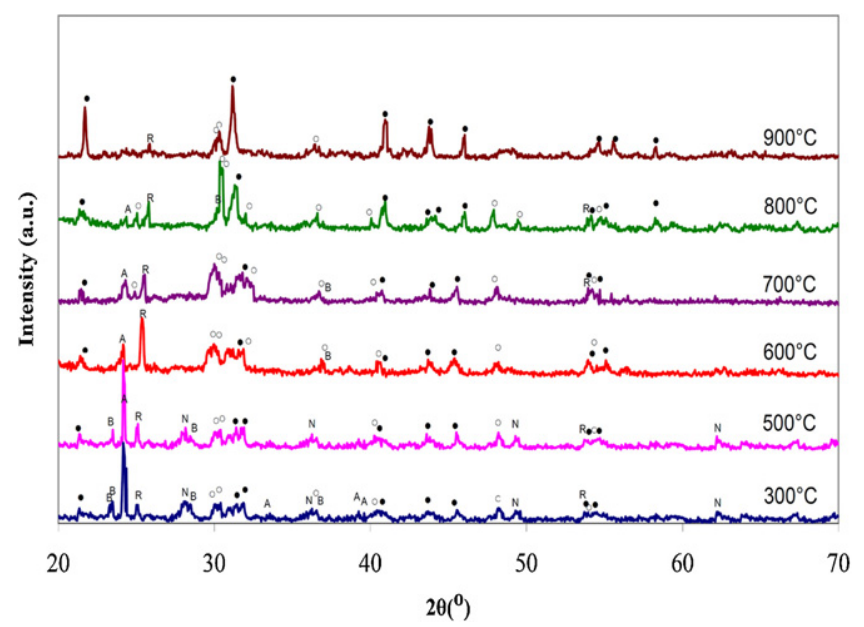

Fig. 5. Room temperature XRD patterns of $10 \mathrm{~h}$ milled samples which are heated up to the temperatures well below and above the temperature ranges of the reactions indicated in the DTA pattern of Fig. 4 and then water quenched.

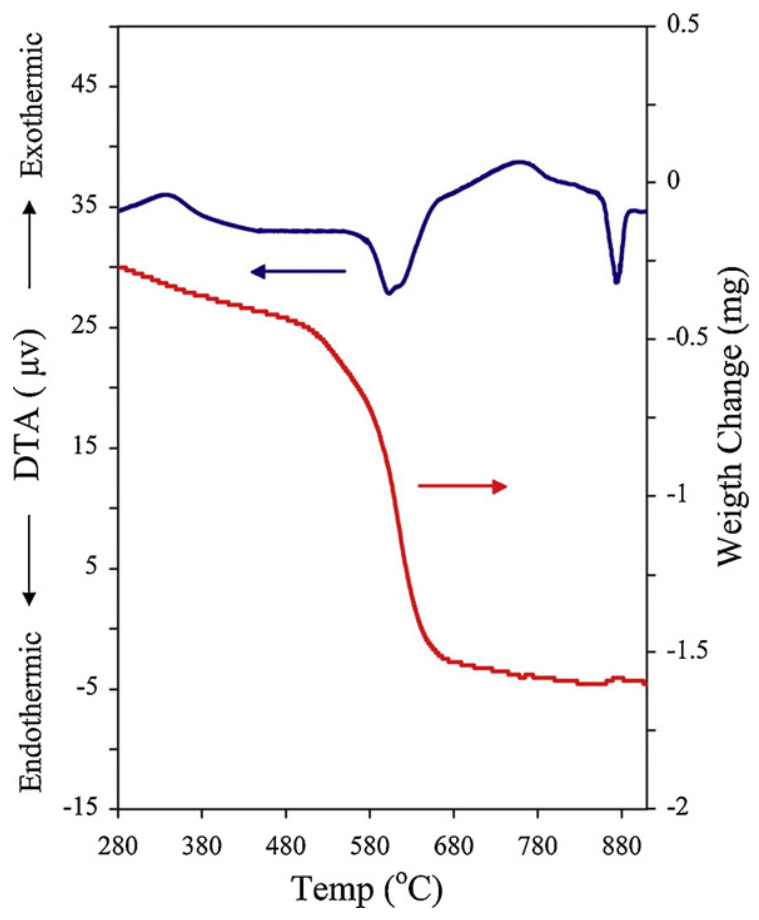

Fig. 6. DTA/TG profiles of $10 \mathrm{~h}$ milled powders.

endothermic peaks disappear while for the exothermic peaks, the intensity of the first one $\left(350^{\circ} \mathrm{C}\right)$ increases and the second one $\left(750^{\circ} \mathrm{C}\right)$ initially increases then retards

Since all the peaks are present in the DTA profile of $10 \mathrm{~h}$ milled sample, it was selected for more interpretation of DTA results. Accordingly, the $10 \mathrm{~h}$ milled samples were heated up to temperatures well below and above the temperature ranges of the reactions (in the same manner as the DTA test) and then quenched in water. Subsequently, XRD analysis was performed on the samples at room temperature (Fig. 5). The only difference between the diffraction patterns of the samples heated up to $300{ }^{\circ} \mathrm{C}$ and $500{ }^{\circ} \mathrm{C}$ is that there is greater peak sharpness in the $500{ }^{\circ} \mathrm{C}$ sample while there is no evidence of phase change during this temperature range. That is, the first exothermic peak is related to stress relaxation during heat treatment in which its intensity increases by milling evolution. In the XRD pattern of the sample heated up to $600{ }^{\circ} \mathrm{C}$, compared to $500{ }^{\circ} \mathrm{C}$, the peak intensity of rutile, with respect to that of anatase, grows considerably, thereby indicating that the first endothermic peak is correlated to anataseto-rutile phase transition. Comparing the XRD profiles of the samples heated up to $500{ }^{\circ} \mathrm{C}, 600{ }^{\circ} \mathrm{C}$, and $700{ }^{\circ} \mathrm{C}$ reveals that the second and third endothermic peaks are correlated to $\mathrm{CO}_{2}$ extraction and pyrochlore formation from the primary materials, respectively. The $\mathrm{CO}_{2}$ removal is clearly confirmed by the TG profile of the $10 \mathrm{~h}$ milled sample (Fig. 6). As it can be expected, by increasing milling time, the quantity of primary materials reduces and the alloying process develops; consequently, these endothermic peaks disappear. The differences between the XRD patterns of the samples heated up to $700{ }^{\circ} \mathrm{C}, 800{ }^{\circ} \mathrm{C}$, and $900{ }^{\circ} \mathrm{C}$ demonstrate that the second exothermic peak and the forth endothermic peak corresponds to the crystallization of the amorphous phase and pyrochlore-to-perovskite phase transformation, respectively. Considering the aforementioned results, as milling progresses, the intensity of the DTA peak correlated to the pyrochlore-toperovskite phase transition decreases while the amorphous phase crystallization increases $(60 \mathrm{~h})$ and then reduces $(280 \mathrm{~h})$, confirming the qualitative phase analysis done by XRD. 


\section{Conclusions}

In this work, the $\left(\mathrm{Bi}_{0.5} \mathrm{Na}_{0.5}\right)_{0.94} \mathrm{Ba}_{0.06} \mathrm{TiO}_{3}$ (BNBT6) piezoceramics were successfully synthesized by mechanical alloying a mixture of $\mathrm{TiO}_{2}, \mathrm{Bi}_{2} \mathrm{O}_{3}, \mathrm{Na}_{2} \mathrm{CO}_{3}$, and $\mathrm{BaO}$. Afterwards, their structural, microstructural and thermal behaviors were evaluated. The results can be summarized as follows:

1) At short milling times, the constituents were directly transformed to perovskite BNBT and some intermediate phases such as BNT and pyrochlore phases.

2) Besides the crystalline phases, an amorphous phase was also created during the milling cycle and it reaches its maximum amount at medium stages of milling.

3) By progression of MA, the perovskite BNBT phase developed due to crystallization of the amorphous phase and, sub-sequently, the pyrochlore-to-perovskite phase transformation occurred.

4) After total dissolution of $\mathrm{r}-\mathrm{TiO}_{2}$ and consequently completion of MA, a single crystalline perovskite BNBT phase was developed. However, the existence of a considerable amount of the amorphous phase was also confirmed at this time.

5) During the milling cycle, polymorphic transformations of $\mathrm{TiO}_{2}$ occurred which act as the main impediment of the alloying process.

6) During the heating cycle, some of these transformations (not all of them), such as the stress relaxation, anatase-to-rutile phase transition, $\mathrm{CO}_{2}$ extraction and pyrochlore formation, crystallization of the amorphous phase, and pyrochlore-to-perovskite phase transformation can occur in the as-milled powders depend on the milling time, confirming the structural analysis done by XRD.

7) The MA method has the ability to synthesize the BNBT powder with submicron particle size, regular morphology, and completely homogeneous distribution of elements.

\section{Acknowledgments}

The authors gratefully acknowledge the financial support received from Iran National Science Foundation (INSF).

\section{References}

[1] S.Q. Zhang, W.D. Fei, W.L. Li, J.N. Wang, J. Alloys Compd. 487 (2009) 703-707.

[2] A.K. Singh, J. Alloys Compd. 509 (2011) 5167-5172.

[3] Y. Cheng, Y. Yang, Y. Wang, H. Meng, J. Alloys Compd. 508 (2010) 364-369.

[4] P.K. Panda, J. Mater. Sci. 44 (2009) 5049-5062.

[5] T. Takenaka, H. Nagata, J. Eur. Ceram. Soc. 25 (2005) 2693-2700.

[6] G.A. Smolenskii, V.A. Jsupov, A.I. Agranovskaya, N.N. Kainik, Phys. Solid State 2 (1961) 2651-2654.

[7] T. Takenaka, Ferroelectrics 230 (1999) 389-400.

[8] T. Takenaka, K. Maruyama, K. Sakata, Jpn. J. Appl. Phys. 30 (1991) 2236-2239.

[9] H. Yan, D. Xiao, P. Yu, J. Zhu, D. Lin, G. Li, Mater. Design. 26 (2005) 474-478.

[10] S. Trujillo, J. Kreisel, Q. Jiang, J.H. Smith, P.A. Thomas, P. Bouvier, F. Weiss, J. Phys. Condens. Matter 17 (2005) 6587-6597.

[11] L. Huidong, F. Chude, Y. Wenlong, Mater. Lett. 58 (2004) 1194-1198.

[12] X.X. Wang, S.W. Or, X.G. Tang, H.L.W. Chan, P.K. Choy, P.C.K. Liu, Solid State Commun. 134 (2005) 659-663.

[13] J. Abe, M. Kobune, T. Nishimura, T. Yazaw, Y. Nakai, Integr. Ferroelectr. 80 (2006) 87-95.

[14] X.X. Wang, H.L.W. Chan, C.L. Choy, Appl. Phys. A: Mater. Sci. Process. 80 (2005) 333-336.

[15] J. Abe, M. Kobune, T. Yazawa, Y. Nakai, S. Osaka, J. Korean Phys. Soc. 46 (2005) $138-142$.

[16] D.L. West, D.A. Payne, J. Am. Ceram. Soc. 86 (2003) 192-194.

[17] S. Saïd, J.P. Mercurio, J. Eur. Ceram. Soc. 21 (2001) 1333-1336.

[18] Y.J. Ma, J.H. Cho, Y.H. Lee, B.I. Kim, Mater. Chem. Phys. 98 (2006) 5-8.

[19] Q. Xu, S. Chen, W. Chen, D. Huang, J. Zhou, H. Sun, Y. Li, J. Mater. Sci. 41 (2006) 6146-6149.

[20] C.Y. Kim, T. Sekino, K. Niihara, J. Am. Ceram. Soc. 86 (2003) 1464-1467.

[21] P. Nandi, P.P. Chattopadhyay, P.M.G. Nambissan, F. Banhart, H.J. Fecht, I. Manna, J. Non-Cryst. Solids 351 (2005) 2485-2492.

[22] R. Amini, M.J. Hadianfard, E. Salahinejad, M. Marasi, T. Sritharan, J. Mater. Sci. 44 (2009) 136-148.

[23] C. Suryanarayana, J. Mater. Sci. 46 (2001) 1-184.

[24] L.B. Kong, J. Ma, H. Huang, R.F. Zhang, Mater. Res. Bull. 37 (2002) 1085-1092.

[25] J. Wang, W. Dongmei, X. Junmin, N.W. Beng, J. Am. Ceram. Soc. 82 (2) (1999) 477-479.

[26] L. Liu, M. Wu, Y. Huang, L. Fang, H. Fan, H. Dammak, M.Ph. Thi, Mater. Res. Bull. 46 (2011) 1467-1472.

[27] L.B. Kong, J. Ma, W. Zhu, O.K. Tan, Mater. Res. Bull. 36 (2001) 1675-1685.

[28] S.E. Lee, J.M. Xue, D.W. Wan, J. Wang, Acta Mater. 47 (9) (1999) 2633-2639.

[29] T. Rojac, M. Kosec, B. Malič, J. Holc, Mater. Res. Bull. 40 (2005) 341-345.

[30] P.M. Botta, E.F. Aglietti, J.M. Porto López, Mater. Res. Bull. 41 (2006) 714-723.

[31] B.D. Stojanovic, J. Mater. Process. Technol. 143-144 (2003) 78-81.

[32] J. Karch, R. Birringer, H. Gleiter, J. Nat. 330 (1987) 556-558.

[33] D. Kuscer, E.T. Sturm, J. Kovac, M. Kosec, J. Am. Ceram. Soc. 92 (6) (2009) 1224-1229.

[34] R. Ren, Z. Yang, L.L. Shaw, J. Mater. Sci. 35 (2000) 6015-6026

[35] S. Begin-Colin, T. Girot, G. Le Caer, A. Mocellin, J. Solid State Chem. 149 (2000) 41-48. 